
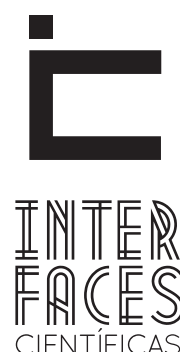

HUMANASE SOCIAIS

\title{
TAXONOMIZANDO SUJEITOS: NOTAS SOBRE OS INVESTIMENTOS DOS SISTEMAS CLASSIFICATÓRIOS PSIQUIÁTRICOS NA REGULAC̄̃̃O DAS TRANSEXUALIDADES E TRAVESTILIDADES
}

André Filipe dos Santos Leite ${ }^{1}$

\section{RESUMO}

Inspirados em pressupostos teórico-metodológicos queer, nosso objetivo neste artigo é analisar os sistemas classificatórios em psiquiatria, que reduzem transexuais e travestis a protocolos clínicos homogêneos. Ao longo das análises do CID-10, DSM-IV-TR e SOC, percebemos o quanto esses dispositivos se colocam enquanto tecnologias que expressam uma concepção normativa dos sistemas sexo-sexualidade-gênero fundamentada numa matriz binária hierarquizante, que se converte em um sistema regulador e medicalizador das experiências trans. Desta forma, apontamos para a necessidade de despatologização desses sujeitos, argumentando que os modos de vida trans não necessariamente fixam posições subjetivas ou entidades clínicas.

\section{PALAVRAS-CHAVE}

Transgêneros. Psiquiatria. CID-10. DSM-IV-TR. SOC. 


\section{ABSTRACT}

Inspired by queer theoretical and methodological assumptions, our objective in this article is to review the classification systems in psychiatry that reduce transsexuals and transvestites to homogeneous clinical protocols. Throughout the analysis of the CID-10, DSM-IVTR and SOC, we realize how much these devices arise as technologies that express a normative conception of the systems gender-sexuality-gender based on a hierarchical binary matrix, which converts into a system medicalization regulator and trans experiments. Thus, we point to the need for depathologization these subjects, arguing that trans lifestyles not necessarily fix subjective positions or clinical entities.

\section{KEYWORDS}

Transgender. Psychiatry. CID-10. DSM-IV-TR. SOC.

\section{RESUMEN}

Inspirados en los presupuestos teóricos y metodológicos queer, nuestro objetivo en este trabajo es analizar los sistemas de clasificación en psiquiatría, que reducen transexuales y travestis a protocolos clínicos homogéneos. A través del análisis de la CIE-10, DSM-IV-TR y SOC, nos damos cuenta de lo mucho que estos dispositivos se colocan como las tecnologías que expresan una concepción normativa de los sistemas de sexo-sexualidad-género basada en una matriz binaria jerárquica, que se convierte en un sistema regulador y de medicalización de experiencias trans. Por lo tanto, señalamos la necesidad de despatologización de estos sujetos, con el argumento de que los estilos de vida trans no necesariamente se fijan en posiciones subjetivas o entidades clínicas.

\section{PALABRAS CLAVE}

Transgénero. Psiquiatría. CIE-10. DSM-IV-TR. SOC. 


\section{INTRODUÇÃO}

A Psiquiatria Moderna, filha de Philippe Pinel, tem seus primórdios nos idos de 1793, quando este se tornou diretor do Bicêtre (GAUCHET, SWAIN, 1980), um asilo psiquiátrico localizado na capital francesa, destinado apenas para homens. Num ato simbólico, Pinel desacorrentou os 'loucos' e impôs uma nova forma de ver, lidar e agir com esses sujeitos (FOUCAULT, 2000), marcando assim o nascimento da clínica psiquiátrica moderna. Mais de dois séculos depois, e seguido das incursões posteriores de Esquirol, Bayle, Morel e outros, a Psiquiatria foi se fortalecendo com campo de atuação médica voltada para a prevenção, atendimento, diagnóstico, tratamento e reabilitação das diferentes formas de sofrimentos mentais (BERCHERIE, 1989), ou para os mais críticos, como Foucault (2001), uma ciência voltada para a regulação e gerenciamento das condutas, comportamentos e anormalidades.

Seria apenas em 1883 que Kraepelin, após a realização de um gigantesco trabalho descritivo e classificatório, constituiria as bases da semiologia psiquiátrica, delineando as formas da psiquiatria contemporânea (SHORTER, 1997). Seu famoso 'Tratado de Psiquiatria' (KRAEPELIN, 1904) estabeleceu um sólido sistema nosográfico, ao qual se referenciaram todas as principais correntes psiquiátricas posteriores e de onde são filhos diretos os sistemas classificatórios hodiernos com os quais os psiquiatras contemporâneos trabalham, principalmente, a saber: o CID-10 e o DSM-IV. É na análise desses dois manuais classificatórios somados a um terceiro, denominado State of Care (SOC) - editado pela HBIGDA desde 1979 para dar conta especialmente da transexualidade -, que aqui nos deteremos para delinear o papel e as incursões da psiquiatria na construção de sujeitos enquanto espécimes psicopatológicas, a partir de suas experiências de gênero.

0 objetivo deste artigo é analisar esses manuais, ressaltando suas fragilidades, fraturas e descontinuidades; mostrando quão débeis e precárias são suas prescrições que tentam a todo custo subsumir as experiências trans a protocolos clínicos homogêneos.

A partir de uma perspectiva metodológica queer, pretendemos desconstruir aquilo que é prescrito nos manuais psiquiátricos, desnaturalizando suas concepções fixas e lineares sobre os corpos e sujeitos trans. Uma perspectiva queer nos chama a "explicitar os modos pelos quais alguns corpos são produzidos como normais à custa da constituição de outros como anormais" (REIS, 2011, p. 49). Assim, enfocaremos os processos de classificação, hierarquização, normalização e regulação instituídos pelos manuais psiquiátricos aos modos de vida trans de modo a expor a produção cultural e discursiva daquilo que é tido como essência e verdade nas experiências trans.

É no compromisso de desconstruir as posições de sujeito estáveis, coerentes e imutáveis prescritas pelos protocolos psiquiátricos e com o objetivo de convocar os sujeitos a estranhar o que está posto como verdade e como saber incontestável sobre as subjetividades que recorremos a essa crítica queerde análise dos sistemas classificatórios psiquiátricos voltados à regulação das transexualidades e travestilidades.

\section{CLASSIFICANDO VIDAS 'SINCE FOREVER’: UM BREVE PANORAMA HISTÓRICO DOS SISTEMAS CLASSIFICATÓRIOS EM PSIQUIATRIA}

O primeiro sistema classificatório que analisaremos é a Classificação Estatística Internacional de Doenças e Problemas Relacionados à Saúde (CID), editada pela Organização Mundial de Saúde (OMS) e hoje em sua décima edição. A CID tem como objetivo estabelecer uma uniformização terminológica quanto à nomenclatura das doenças de uma forma geral, permitindo melhor troca de informações sobre o conhecimento de uma doença específica 
quanto a sua história natural, maneiras de diagnosticar, tratar e prevenir (OMS, 1993).

Em termos históricos, a CID-10 teve seus primórdios em 1893, com a Classification of Bertillon ou International List of Causes of Death (ICD), a qual apresentava apenas 161 categorias (LAURENTI, 1991). Em 1948, quando de sua sexta edição, tal classificação passa a ser instituída pela OMS e se denomina International Statistical Classification of Diseases, Injuries and Causes of Death (ICD-6), contando já com 1010 categorias, incluindo uma inédita seção especial para a classificação dos transtornos mentais, antes não abarcados (DI NUBILA, BUCHALLA, 2008).

As transexualidades e travestilidades só vêm figurar nos manuais da CID em sua última e mais recente versão: CID-10, de 1992, que, em seu Capítulo V, dos 'Transtornos Mentais e do Comportamento', inclui nos chamados Transtornos da Identidade Sexual, regidos pelo código F64, os: ‘Transexualismo' (F64.0), 'Travestismo Bivalente' (F64.1), 'Transtorno de identidade sexual na infância' (F64.2), 'Outros transtornos de identidade sexual' (F64.8), e o 'Transtorno não especificado da identidade sexual’ (F64.9) (OMS, 1993).

O Manual Diagnóstico e Estatístico de Transtornos Mentais (DSM), por sua vez, tem raízes norte-americanas e, diferentemente da CID, tende a ser um manual classificatório específico para os transtornos mentais. Publicado pela primeira vez em 1952, pela Associação Americana de Psiquiatria (APA), tem sua gênese histórica num antigo sistema de classificação de 1918 utilizado pelo Departamento de Censo Americano para uniformizar estatísticas vindas de hospitais psiquiátricos (HENRIQUES, 2012). Apenas em 1980, com a terceira edição do DSM, é que a transexualidade e a travestilidade passam a compor os cânones da psicopatologia norte-americana.

Sua última edição em português (DSM-IV), de 1994, e posterior edição revisada, de 2000 (DMS-IV-TR), ainda definem as experiências trans dentro do grupamento dos Transtornos Sexuais. A transexualidade aparece como 'Transtorno da Identidade de Gênero', sob os códigos diagnósticos: 302.6 caso o transtorno ocorra na infância e 302.85 para o adolescente ou adulto e à travestilidade cabe a nomenclatura 'Travestismo Fetichista', 302.3. O DSM conta ainda com a existência de uma categoria para os sujeitos que não atendem a todos os critérios: 'Transtorno da Identidade de Gênero sem outra especificação’ (APA, 2002).

Especificamente no que se refere à transexualidade, além dos manuais já citados, ainda existe um terceiro protocolo, conhecido como StateofCare (SOC), que aqui também será investigado. Já em sua sexta edição, o SOC é editado pela associação norte-americana Harry Benjamin International Gender Dysphoria Association (HBIGDA) desde 1979, contando com versões posteriores em 1980, 1981, 1990, 1998 e a última em 2001. Ao contrário do CID-10 e do DSM-IV, que se dedicam a catalogar múltiplos comportamentos considerados transtornos, o SOC reúne um conjunto de orientações, exclusivamente sobre as questões referentes aos ‘transtornos de gênero' (HBIGDA, 2014).

O propósito do SOC vai além de articular um consenso profissional internacional acerca do manejo psiquiátrico, clínico, cirúrgico e psicológico das transexualidades, este manual objetiva, também, orientar familiares e instituições sociais sobre como 'lidar' com as pessoas ‘disfóricas de gênero’ (HBIGDA, 2014).

\section{HOMOGENEIZANDO EXISTÊNCIAS: OQUE DIZEM OS MANUAIS?}

'Transexualismo', 'Transtorno da Identidade Sexual', 'Travestismo Bivalente', 'Travestismo Fetichista', 'Disforia de Gênero', inúmeras são as classificações que visam normatizar, normalizar e regular as experiências trans. 0 que assistimos, contemporaneamente, é uma crescente proliferação de novas categorias médico-psiquiátricas que seguem patologizando comportamentos, vivências e experiências a partir de 
um pressuposto heteronormativo que exige uma linearidade sem fissuras entre genitálias, sexos, sexualidades, gêneros, desejos e práticas erótico-sexuais (BUTLER, 2003). De uma forma ou de outra, nesses três documentos - CID-10, DSM-IV-TR e SOC -, as pessoas transexuais e travestis são construídas como portadoras de um conjunto de indicadores comuns que as posicionam como transtornadas, independentemente de variáveis culturais, sociais e econômicas.

Contudo, há algumas diferenças entre esses documentos. Para o SOC, que não se refere diretamente à travestilidade, o 'transexual de verdade' tem como única alternativa para resolver seus 'transtornos' ou 'disforias' a cirurgia de transgenitalização. Já no DSM-IV-TR, a questão da cirurgia é apenas tangenciada, sua preocupação principal está em apontar as manifestações do ‘transtorno' na infância, na adolescência e na fase adulta. O CID-10, por sua vez, é o documento mais objetivo, apresentando sumariamente as características gerais dos referidos transtornos.

F64.0 Transexualismo

Trata-se de um desejo de viver e ser aceito enquanto pessoa do sexo oposto. Este desejo se acompanha em geral de um sentimento de mal estar ou de inadaptação por referência a seu próprio sexo anatômico e do desejo de submeter-se a uma intervenção cirúrgica ou a um tratamento hormonal a fim de tornar seu corpo tão conforme quanto possível ao sexo desejado.

F64.1 Travestismo bivalente

Este termo designa o fato de usar vestimentas do sexo oposto durante uma parte de sua existência, de modo a satisfazer a experiência temporária de pertencer ao sexo oposto, mas sem desejo de alteração sexual mais permanente ou de uma transformação cirúrgica; a mudança de vestimenta não se acompanha de excitação sexual. Transtorno de identidade sexual no adulto ou adolescente, tipo não-transexual. Exclui: travestismo fetichista (F65.1)

F64.2 Transtorno de identidade sexual na infância Transtorno que usualmente primeiro se manifesta no início da infância (e sempre bem antes da puberdade), caracterizado por um persistente em intenso sofrimento com relação a pertencer a um dado sexo, junto com o desejo de ser (ou a insistência de que se é) do outro sexo. Há uma preocupação persistente com a roupa e as atividades do sexo oposto e repúdio do próprio sexo. 0 diagnóstico requer uma profunda perturbação de identidade sexual normal; não é suficiente que uma menina seja levada ou traquinas ou que o menino tenha uma atitude afeminada. Os transtornos da identidade sexual nos indivíduos púberes ou pré-púberes não devem ser classificados aqui mas sob a rubrica F66. Exclui: orientação sexual egodistônica (F66.1) e transtorno da maturação sexual (F66.0). (OMS, 1992, on-line).

Ainda que, como dito, o CID-10 não seja um manual de orientação ou de indicadores diagnósticos nem um protocolo psiquiátrico específico, sendo, na realidade, uma convenção médica que estabelece as características das doenças e seus respectivos códigos utilizados e aceitos por médicos internacionalmente, suas considerações sobre as experiências trans, inscritas de maneira universal, criam tipos específicos de sujeitos unos e imutáveis. Instauram-se novas espécies na taxonomia dos corpos sexualizados e generificados, reiterando a medicalização das condutas sexuais. No discurso do CID-10, essas novas espécies apresentam determinadas características fixas que as qualificam e as identificam de forma segura em detrimento de outras espécies sexuais, também delimitadas e fixas.

Ao colocar como diretrizes para a transexualidade o "desejo de viver e ser aceito enquanto pessoa do sexo oposto", "sentimento de mal estar ou de inadaptação por referência a seu próprio sexo anatômico" e "desejo de submeter-se a uma intervenção cirúrgica ou a um tratamento hormonal" e para a travestilidade "usar vestimentas do sexo oposto durante uma parte de sua existência, de modo a satisfazer a experiência temporária de pertencer ao sexo oposto" e "sem desejo de alteração sexual mais permanente ou de uma transformação cirúrgica”, no CID-10 desenham-se fios que se alinhavam na construção de um diagnóstico que é definido por “uma concepção normativa seja dos sistemas de sexo-gênero, seja do dispositivo da diferença sexual" (ARÁN, 2006, p. 49), um diagnóstico que "fundado numa matriz binária heterossexual, se converte em sistema regulador da sexualidade e da subjetividade" (ARÁN, 2006, p. 50). 
Será mesmo que todos os indivíduos que se autodeclaram transexuais ou travestis correspondem e atendem a todas essas prerrogativas? E seria mesmo necessário que para serem considerados travestis ou transexuais eles tenham que atender a todos esses critérios? Aliás, qual a real necessidade dessas prerrogativas e critérios?

O DSM-IV-TR apresenta definições mais extensas e detalhadas no que viria a ser o 'fenômeno transexual' (BENJAMIN, 1966), inicialmente como características diagnósticas, o manual nos ensina que:

Há dois componentes no Transtorno da Identidade de Gênero, sendo que ambos devem estar presentes para fazer o diagnóstico.

Deve haver evidências de uma forte e persistente identificação com o gênero oposto, que consiste do desejo de ser, ou a insistência do indivíduo de que ele é do sexo oposto (Critério A).

Esta identificação com o gênero oposto não deve refletir um mero desejo de quaisquer vantagens culturais percebidas por ser do outro sexo. Também deve haver evidências de um desconforto persistente com o próprio sexo atribuído ou uma sensação de inadequação no papel de gênero deste sexo (Critério B).

O diagnóstico não é feito se o indivíduo tem uma condição intersexual física concomitante (por ex., síndrome de insensibilidade aos andrógenos ou hiperplasia adrenal congênita) (Critério C).

Para que este diagnóstico seja feito, deve haver evidências de sofrimento clinicamente significativo ou prejuízo no funcionamento social ou ocupacional ou em outras áreas importantes da vida do indivíduo (Critério D). (APA, 2002, on-line).

Já desde sua terceira versão, conforme constatado por Russo (2004), o DSM tem caminhado para uma visão biologizante de seus diagnósticos, situação da qual os transtornos sexuais não poderiam escapar. Tal declinação biologizante se expressa nitidamente em dois momentos: primeiro na linearidade exigida pelo critério $A$, entre genitália anatômica e expressão de gênero, nos mostrando o quanto são os deslocamentos do gênero em relação ao sexo biológico os definidores do transtorno, pois, o gênero 'normal' só existe quando referenciado a um sexo genital que o estabiliza. Segundo, a partir da confusão entre as categorias sexo, sexualidade e gênero, presente em todo o documento: "identificação com o gênero oposto", "a insistência do indivíduo de que ele é do sexo oposto" (RUSSO, 2004, p. 42).

Os demais critérios, também, são controversos; afinal, quais seriam essas 'vantagens culturais percebidas por ser do outro sexo' num mundo marcado pela diferença sexual rígida que não admite o atravessamento de fronteiras? E que 'sofrimento clinicamente significativo' é esse? 0 sofrimento psíquico, na maior parte das vezes oriundo de dinâmicas sociais que violentam e subalternizam esses sujeitos, deveria figurar, assim, dentro do rol de definições unívocas para a legitimação dos sujeitos enquanto transexuais?

Após a caracterização das normativas diagnósticas, o DSM-IV-TR identifica a presença do 'transtorno' por fases da vida. Na infância:

\begin{abstract}
Em meninos, a identificação com o gênero oposto é manifestada por uma acentuada preocupação com atividades tradicionalmente femininas. Eles podem manifestar uma preferência por vestir-se com roupas de meninas ou mulheres ou improvisar esses itens a partir de materiais disponíveis, quando os artigos genuínos não estão à sua disposição. Toalhas, aventais e lenços frequentemente são usados para representar cabelos longos ou saias. Existe uma forte atração pelos jogos e passatempos estereotípicos de meninas. Pode ser observada uma preferência particular por brincar de casinha, desenhar meninas bonitas e princesas e assistir televisão ou vídeos de suas personagens femininas favoritas. Bonecas estereotipicamente femininas, tais como Barbie, com frequência, são seus brinquedos favoritos, e as meninas são suas companhias preferidas. Quando brincam de casinha, esses meninos encenam figuras femininas, mais comumente 'papéis de mãe', e habitualmente ocupam sua fantasia com figuras femininas. Esses meninos evitam brincadeiras rudes e esportes competitivos e demonstram pouco interesse por carrinhos ou caminhões ou outros brinquedos não-agressivos, porém estereotipicamente masculinos. Eles podem expres-
\end{abstract}


sar um desejo de ser meninas e declarar que, quando crescerem, serão mulheres. Pode haver, também, uma insistência em urinar sentados e em fingir que não possuem pênis, escondendo-o entre as pernas. Mais raramente, os meninos com Transtorno da Identidade de Gênero podem afirmar que têm aversão por seu pênis ou testículos, que desejam removê-los ou que têm, ou desejam ter, uma vagina.

As meninas com Transtorno da Identidade de Gênero apresentam reações negativas intensas às expectativas ou tentativas dos pais de que se vistam com roupas femininas. Algumas podem recusar-se a comparecer à escola ou a eventos sociais em que essas roupas são exigidas. Elas preferem roupas de menino e cabelos curtos e com frequência são erroneamente identificadas por estranhos como meninos; elas também podem pedir aos outros que as chamem por nomes masculinos. Seus heróis de fantasia são, com maior frequência, figuras masculinas poderosas, tais como Batman ou Super-Homem. Essas meninas preferem brincar com meninos, e com eles compartilham interesses em esportes de contato, brincadeiras rudes e jogos tradicionalmente masculinos. Elas demonstram pouco interesse em bonecas ou em qualquer forma de roupas ou atividades femininas de faz-de-conta. Uma menina com este transtorno pode recusar-se, ocasionalmente, a urinar sentada. Ela pode afirmar que tem ou terá um pênis e não desejar desenvolver seios ou menstruar. Ela pode declarar que quando crescer será um homem. Essas meninas tipicamente revelam acentuada identificação com o gênero oposto em brincadeiras, sonhos e fantasias. (APA, 2002, on-line).

0 que se observa nessas orientações dadas pelo DSM acerca de que sinais denunciariam uma possível transexualidade infantil é que esses sinais são comportamentos culturalmente construídos, que por situações arbitrárias ao longo da história se correlacionaram apenas a determinados gêneros específicos (PELÚCIO, 2009), a discordância desse aspecto historicamente construído é que então aqui figura sob a alcunha de patologia. Ao discorrer sobre "atividades tradicionalmente femininas" ou "jogos tradicionalmente masculinos" e admitir que as primeiras podem se encontrar em corpos ditos de meninos e que os segundos podem marcar corpos ditos de meninas, o DSM-IV-TR deixa escapar que gênero e sexo não são assim 'naturalmente' conectados ou irremediavelmente atrelados.
Acena, desse modo, para uma ideia de gênero como uma construção social imposta a uma matéria passiva pré-determinada (o sexo), que como construção social pode marcar tanto um corpo com vagina quanto um corpo com pênis; mas que a título da normalidade psiquiátrica deve seguir determinadas normativas em suas filiações. Porém, aqui dilatamos as ideias de gênero para entendê-lo segundo ideais bluterianos (2003), que o colocam como um efeito performático que possibilita a constituição e o reconhecimento de uma trajetória sexuada, a qual adquire estabilidade em função da repetição e da reiteração de normas.

Butler (2003), - a partir de Foucault (2011), para quem, o dispositivo da sexualidade na modernidade só pode ser compreendido por meio dos mecanismos de poder e saber que lhes são intrínsecos -; formulou a noção de um 'gênero' produzido, forjado dentro de uma trama de relações sociais e marcações discursivas que o materializam, por meio de práticas regulatórias reiteradas que produzem, marcam, demarcam, diferenciam os corpos que governa e controla.

O DSM-IV-TR continua seu trabalho de mapear os transtornos de gênero:

Os adultos com Transtorno da Identidade de Gênero preocupam-se com seu desejo de viver como um membro do sexo oposto. Esta preocupação pode manifestar-se como um intenso desejo de adotar o papel social do sexo oposto ou adquirir a aparência física do sexo oposto através de manipulação hormonal ou cirúrgica. Os adultos com este transtorno sentem desconforto ao serem considerados ou funcionarem, na sociedade, como um membro de seu sexo designado. Eles adotam, em variados graus, o comportamento, roupas e maneirismos do sexo oposto. Em sua vida privada, esses indivíduos podem passar muito tempo vestidos como o sexo oposto e trabalhando para que sua aparência seja a do outro sexo. Com roupas do sexo oposto e tratamento hormonal (e, para homens, eletrólise), muitos indivíduos com este transtorno podem passar-se convincentemente por pessoas do sexo oposto. A atividade sexual desses indivíduos com parceiros do mesmo sexo geralmente é limitada pelo fato de preferirem que os parceiros não vejam nem toquem seus genitais. Para alguns homens que apresentam o 
transtorno em uma idade mais tardia (frequentemente após o casamento), a atividade sexual com uma mulher é acompanhada pela fantasia de serem amantes lésbicas ou de que sua parceira é um homem e ele é uma mulher. (APA, 2002, on-line).

A normatividade do binarismo de sexo e de gênero expressa nas linhas desse manual só permitem aos deslocamentos, como a transexualidade e a travestilidade, serem vistos como maneiras de existir desviantes, criando-se categorias linguísticas e psiquiátricas que conferem ininteligibilidade à vivência destas pessoas (PERES, 2012). Se o gênero só consegue sua inteligibilidade quando referido à diferença sexual e à complementaridade dos sexos, quando se produz no menino a masculinidade e na menina a feminilidade, heteronormatividade e normas de gênero se inserem como condições para dar sentido à vida dos sujeitos trans.

Em adolescentes, as características clínicas podem assemelhar-se àqueles de crianças ou de adultos, dependendo do nível de desenvolvimento do indivíduo, devendo os critérios ser aplicados de acordo com o quadro clínico. Em um adolescente mais jovem, pode ser difícil chegar a um diagnóstico correto, em vista de sua reserva, que pode aumentar se ele sentir-se ambivalente acerca da sua identificação com o sexo oposto ou achar que isto é inaceitável para sua família [...]. Nessas circunstâncias, o diagnóstico deve ser reservado para aqueles adolescentes que se mostram bastante identificados com o sexo oposto em seu vestuário ou que se envolvem em comportamentos que sugerem uma significativa identificação com o gênero oposto (por ex., depilar as pernas, em homens). 0 esclarecimento do diagnóstico em crianças e adolescentes pode exigir um extenso período de monitoramento. (APA, 2002, on-line).

Em todas as tentativas de definir crianças, adolescentes ou adultos como portadores do 'transtorno da identidade de gênero', observamos a redução massiva dos sujeitos a determinados códigos instituídos historicamente como femininos ou masculinos, num aprisionamento da experiência travesti e transexual à materialidade do gênero, que é constantemente reconfigurada por aparatos discursivos (BENTO, 2006, 2008). Tais exercícios discursivos de poder - ou biopo- der, se quisermos por em termos de Foucault (2011) -, que corroboram com a sexopolítica de Beatriz Preciado (2011), nos efeitos sobre os corpos sexuados e na normalização das experiências de gênero subversivas, levam a uma ruptura nos significados, posições e papéis de identificação de gênero e sexo, constituindo-se em formas potentes da ação biopolítica.

$\mathrm{Na}$ impossibilidade de justificar os transtornos como disfunções orgânicas a partir de achados biológicos ou de testes clinicamente apropriados e repetíveis, conforme o próprio manual atesta,

Não existe qualquer teste diagnóstico específico para o Transtorno da Identidade de Gênero. Na presença de um exame físico normal, geralmente não se indica 0 cariótipo de cromossomas sexuais e avaliações de hormônios sexuais. A testagem psicológica pode revelar identificação ou padrões de comportamento do gênero oposto [...]. Os indivíduos com Transtorno da Identidade de Gênero têm genitália normal. (APA, 2002, on-line).

O saber-poder médico, então, se utiliza das normas de gênero para construir um parecer sobre os níveis de masculinidade ou feminilidade nos sujeitos demandantes e, dessa forma, forjar um diagnóstico dos gêneros. Se não há nenhum exame clínico que conduza à produção do diagnóstico, porque considerar determinadas experiências de gênero patológicas? 0 que autoriza psiquiatras a rotular existências, além de toda uma discursividade fundamentada em pressupostos culturais, que arbitrariamente alçaram status de saber instituído hegemônico? Como estabelecer os limites discerníveis entre os 'transtornados de gênero' e os 'normais de gênero' sem o risco de cairmos em armadilhas medicalizantes?

A única óptica segura que guia o olhar de médicos psiquiatras e dos membros das equipes multidisciplinares são as convenções socialmente estabelecidas para os gêneros. Logo, estamos diante de um poderoso discurso que tem como finalidade manter os gêneros prisioneiros à diferença sexual. 
No que se refere às travestilidades, o DSM-IV-TR nos apresenta à figura do 'Travestismo Fetichista'. Vale ressaltar, porém, que o CID-10 também se refere à nomenclatura de 'Travestismo Fetichista' (F65.1), mas com algumas diferenças do 'Travestismo Fetichista' caracterizado pelo DSM-IV-TR. Se no CID-10 o mesmo é definido por sujeitos que têm o hábito de

[...] vestir roupas do sexo oposto, principalmente com o objetivo de obter excitação sexual e de criar a aparência de pessoa do sexo oposto. 0 travestismo fetichista se distingue do travestismo transexual pela sua associação clara com uma excitação sexual e pela necessidade de se remover as roupas uma vez que o orgasmo ocorra e haja declínio da excitação sexual. Pode ocorrer como fase preliminar no desenvolvimento do Transexualismo. (OMS, 1992, on-line).

No DSM-IV-TR, por sua vez, o 'Travestismo Fetichista' restringe-se aos homens e se refere aos sujeitos que se utilizam de vestimentas femininas tanto de forma esporádica na obtenção de satisfação sexual quanto de forma mais duradoura, conforme explicitado: "os fenômenos travésticos variam desde o uso ocasional e solitário de roupas femininas até o extenso envolvimento em uma subcultura travéstica" (APA, 2002).

Além da possível inscrição dessa experiência tanto como travestilidade quanto como fetiche, o DSM ainda deixa aberta outras possibilidades patologizantes: "Este transtorno tem sido descrito apenas em homens heterossexuais [...] Embora sua preferência básica seja heterossexual, ele tende a ter poucas parceiras sexuais e pode ter-se envolvido em atos homossexuais ocasionais" (APA, 2002, on-line) - o que nos leva à inscrição da categoria êmica de crossdresser nos termos de uma nosografia psiquiátrica.

O DSM-IV-TR, ainda, ressalta que "em outros indivíduos uma disforia quanto ao gênero pode emergir [...] sendo acompanhada pelo desejo de vestir-se e viver permanentemente como mulher" (APA, 2002, on-line). O que observamos em todas essas orientações do DSM-IV-TR é uma confusão de conceitos e definições calcados em uma normatividade que exige uma linearidade incorruptível entre gênero e genitália, declinando-se a patologizar tudo aquilo que fuja deste imperativo.

Diferente do CID-10 e do DSM-IV-TR, o SOC reúne um conjunto de orientações exclusivamente sobre questões referentes a transtornos de gênero. No entanto, as definições do SOC e do CID-10 são basicamente as mesmas e, embora o SOC utilize 'disforia de gênero' e o CID-10 refira-se a 'transtornos da identidade sexual/transexualismo', não há divergências dignas de notas entre os dois documentos. Inclusive, na construção do diagnóstico, o SOC orienta que quando os "indivíduos insatisfeitos cumprem os critérios especificados nas duas classificações internacionais oficiais (CID-10 e DSM-IV-TR), se pode dizer que sofrem uma desordem da identidade de gênero" (HBIGDA, 2014, on-line).

Afastamentos e aproximações também são observados na relação entre SOC e DSM-IV-TR, se a ênfase na cirurgia, dada pelo SOC como alternativa terapêutica o diferencia do DSM-IV-TR, aproximações são feitas quando ambos reconhecem algumas limitações nos atuais saberes sobre a transexualidade e mantêm esperanças na resolução dessas limitações no futuro por meio da investigação científica.

Ainda da mesma forma que o DSM-IV-TR, o SOC tenta esgotar os indicadores das 'desordens de gênero', ao longo das fases da vida dos sujeitos, fazendo também recomendações para o tratamento adequado dessas pessoas. No que diz respeito a este último aspecto, no entanto, a não figuração da psicoterapia como requisito absoluto no tratamento marca divergências com o DSM-IV-TR.

Divergências essas que têm sua fonte histórica nas raízes de cada um dos manuais. Se o DSM-IV-TR representa uma operacionalização do pensamento do psiquiatra Robert Stoller (1992), a fonte de inspiração do SOC é o endocrinologista Harry Benjamin (1966). Nesse sentido, as várias atualizações do SOC não fogem do aspecto principal formulado por Benjamin 
(1966): a da transexualidade como enfermidade que tem sua origem em alguma parte do corpo e as cirurgias de transgenitalização como as únicas terapias possíveis para essas pessoas.

\section{MANIFESTO PELA DESPATOLOGIZAÇÃO DOS GÊNEROS E SEXUALIDADES: PELO DIREITO DE EXISTIR PARA ALÉM DOS PROTOCOLOS}

Ao longo das linhas deste artigo, percebemos como CID-10, DSM-IV-TR e SOC se colocam claramente como tecnologias que expressam uma concepção normativa dos sistemas sexo-gênero, fundamentada numa matriz binária hierarquizante que se converte em um sistema regulador e medicalizador das sexualidades, dos gêneros e dos sujeitos trans. 0 que tentamos mostrar é que transexualidade e travestilidade não necessariamente fixam posições subjetivas, tais experiências comportam, na realidade, várias formas singulares de subjetivação (ARÁN, ZAIDHAFT, MURTA, 2008).

Portanto, não se deve esperar das/dos transexuais e travestis um comportamento fixo, rígido, adequado a normas de feminilidade ou de masculinidade, definidas culturalmente de forma arbitrária. Mesmo porque, em última instância, em todos esses manuais, o que contribuirá para a formação de um parecer psiquiátrico sobre a veracidade ou não das existências e experiências dos sujeitos demandantes são as normas de gênero. São elas que, a todo o momento, são citadas em séries de efeitos discursivos, que têm o poder de delimitar e viabilizar a vida dos sujeitos.

Mas, e se de repente apostarmos nas debilidades dessas próprias normativas para agenciar formas de atuação na própria psiquiatria que levem em consideração os desejos e aspirações dos sujeitos para além de condutas protocolares documentadas? E se agenciarmos gritos e ecos que evidenciem as debilidades de uma nosologia psiquiátrica prenhe de descontinuidade e ambiguidades? Apostando, conforme nos orienta a crítica queer, nas debilidades e ambivalências dos discursos dos manuais apresentados, podemos apreender como a patologização e psiquiatrização (MURTA, 2007) das experiências trans foram forjadas ao longo da história. E, dessa forma, podemos problematizar o lugar da Psiquiatria como aquela que define, permite, delibera e autoriza a existência e legitimidade de alguns sujeitos em detrimento de outros.

Ora, a busca pelo reconhecimento social dos ditos 'desviantes', no caso específico deste artigo: travestis e transexuais passa justamente por criar um novo campo de inteligibilidade dessas pessoas que escape do estigma da doença. Assim, rumar para a despatologização das experiências trans é um imperativo político e ético. Ético, pois viabiliza a saída desses sujeitos da categoria de 'monstros' (LEITE JR, 2011), de transtornados psiquiátricos (BENTO, PELÚCIO, 2012), e político, pois aponta para a possibilidade de esses sujeitos conseguirem habitar integral e legitimamente a categoria de 'humanos'. Para isso, é fundamental a despatologização não só das travestilidades e transexualidades como também das intersexualidades e de todas as formas possíveis de existir que encenem cruzamentos e atravessamentos entre as sexualidades e os gêneros.

\section{REFERÊNCIAS}

AMERICAN PSYCHIATRIC ASSOCIATION. Manual Diagnóstico e Estatístico de Transtornos Mentais (DSM-IV-TR). Porto Alegre: Artmed, 2002.

ARÁN, M. A Transexualidade e a gramática normativa do sistema sexo-gênero. Ágora, Vitória, v.9, n.1, 2006. p.49-63.

ARÁN, M.; ZAIDHAFT, S.; MURTA, D. Transexualidade: corpo, subjetividade e saúde coletiva. Psicologia \& Sociedade, Porto Alegre, v.20, n.1, 2008. p.70-79.

BENJAMIN, H. The Transsexual Phenomenon. New York: Julian Press, 1966. 
BENTO, B. 0 que é transexualidade. São Paulo: Brasiliense, 2008.

BENTO, B. A reinvenção do corpo: sexualidade e gênero na experiência transexual. Rio de Janeiro: Garamond, 2006.

BENTO, B.; PELÚCIO, L. Despatologização do gênero: a politização das identidades abjetas. Rev. Est. Fem., v.20, n.2, Florianópolis, 2012.

BERCHERIE, P. Os fundamentos da clínica: história e estrutura do saber psiquiátrico. Rio de Janeiro: Jorge Zahar, 1989.

BUTLER, J. Problemas de gênero: feminismo e subversão da identidade. Rio de Janeiro: Civilização Brasileira, 2003.

DI NUBILA, H. B. V.; BUCHALLA, C. M. O papel das Classificações da OMS - CID e CIF nas definições de deficiência e incapacidade. Rev. Bras. Epidemiol. v.11, n.2, São Paulo, 2008.

FOUCAULT, M. História da sexualidade I: a vontade de saber. Rio de Janeiro: Graal, 2011.

FOUCAULT, M. História da loucura na Idade Clássica. São Paulo: Perspectiva, 2000.

FOUCAULT, M. Os anormais: curso no Collège de France (1974 - 1975). São Paulo: Martins Fontes, 2001.

GAUCHET, M.; SWAIN, G. La pratique de l'esprithumain: L'instituitionasilaireet la revolution démocratique. Paris: Gallimard, 1980.

HENRIQUES, R. P. Psicopatologia crítica: guia didático para estudantes e profissionais de psicologia. São Cristovão: UFS, 2012.

HIBGDA - HARRY BENJAMIN INTERNATIONAL GENDER DYSPHORIA ASSOCIATION. State of
Care (SOC). Disponível em: <http://www.tc.umn edu/ colem001/hbigda/hstndrd.htm>. Acesso em: 1 abr. 2014

KRAEPELIN, E. Trattato di Psichiatria. Milano: Casa Editrice Dottor Francesco Vallardi, 1904.

LAURENTI, R. Análise da informação em saúde: 1893-1993, cem anos da Classificação Internacional de Doenças. Rev. Saúde Pública, v.25, n.6, São Paulo, 1991.

LEITE JR., J. Nossos corpos também mudam: a invenção das categorias "travesti e "transexual" no discurso científico. São Paulo: Annablume/FAPESP, 2011.

MURTA, D. A Psiquiatrização da transexualidade: análise dos efeitos do diagnóstico de transtorno de identidade de gênero nas práticas de saúde. 2007. Dissertação (Mestrado em Saúde Coletiva) - Universidade do Estado do Rio de Janeiro, Rio de Janeiro, 2007.

ORGANIZAÇÃO MUNDIAL DE SAÚDE. Classificação Estatística Internacional de Doenças e Problemas Relacionados à Saúde (CID-10). Porto Alegre: Artes Médicas, 1993.

PELÚCIO, L. Abjeção e desejo: uma etnografia travesti sobre o modelo preventivo da aids. São Paulo: Annablume/FAPESP, 2009.

PERES, W. S. Travestilidades nômades: a explosão dos binarismos e a emergência queering. Rev. Estud. Fem., v.20, n.2, 2012. p.539-547.

PRECIADO, B. Multidões queer: notas para uma política dos “anormais”. Rev. Estud. Fem., v.19, n.1, 2011.

REIS, C. D. O uso da metodologia queer em pesquisas no campo do currículo. In: MEYER, D.; PARAÍSO, M. (Org.). Metodologias de pesquisas pós-críticas em educação. Belo Horizonte: Mazza, 2012. 
RUSSO, J. A. Do desvio ao transtorno: a medicalização da sexualidade na nosografia psiquiátrica contemporânea. In: PISCITELLI, A.; GREGORI, M. F.; CARRARA, S. (Org.). Sexualidade e saberes: convenções e fronteiras. Rio de Janeiro: Garamond, 2004.
SHORTER, E. The history of psychiatry: from the Era of the Asylum to the Age of Prozac. New York: John Wiley and Sons, 1997.

STOLLER, R. A experiência transexual. Rio de Janeiro: Imago, 1992. 